This item was submitted to Loughborough's Research Repository by the author.

Items in Figshare are protected by copyright, with all rights reserved, unless otherwise indicated.

\title{
Calculating the failure intensity of a non-coherent fault tree using the BDD technique.
}

PLEASE CITE THE PUBLISHED VERSION

PUBLISHER

(C) Loughborough University

LICENCE

CC BY-NC-ND 4.0

REPOSITORY RECORD

Beeson, Sally C., and J.D. Andrews. 2008. "Calculating the Failure Intensity of a Non-coherent Fault Tree Using the BDD Technique.". figshare. https://hdl.handle.net/2134/3639. 
This item was submitted to Loughborough's Institutional Repository by the author and is made available under the following Creative Commons Licence conditions.

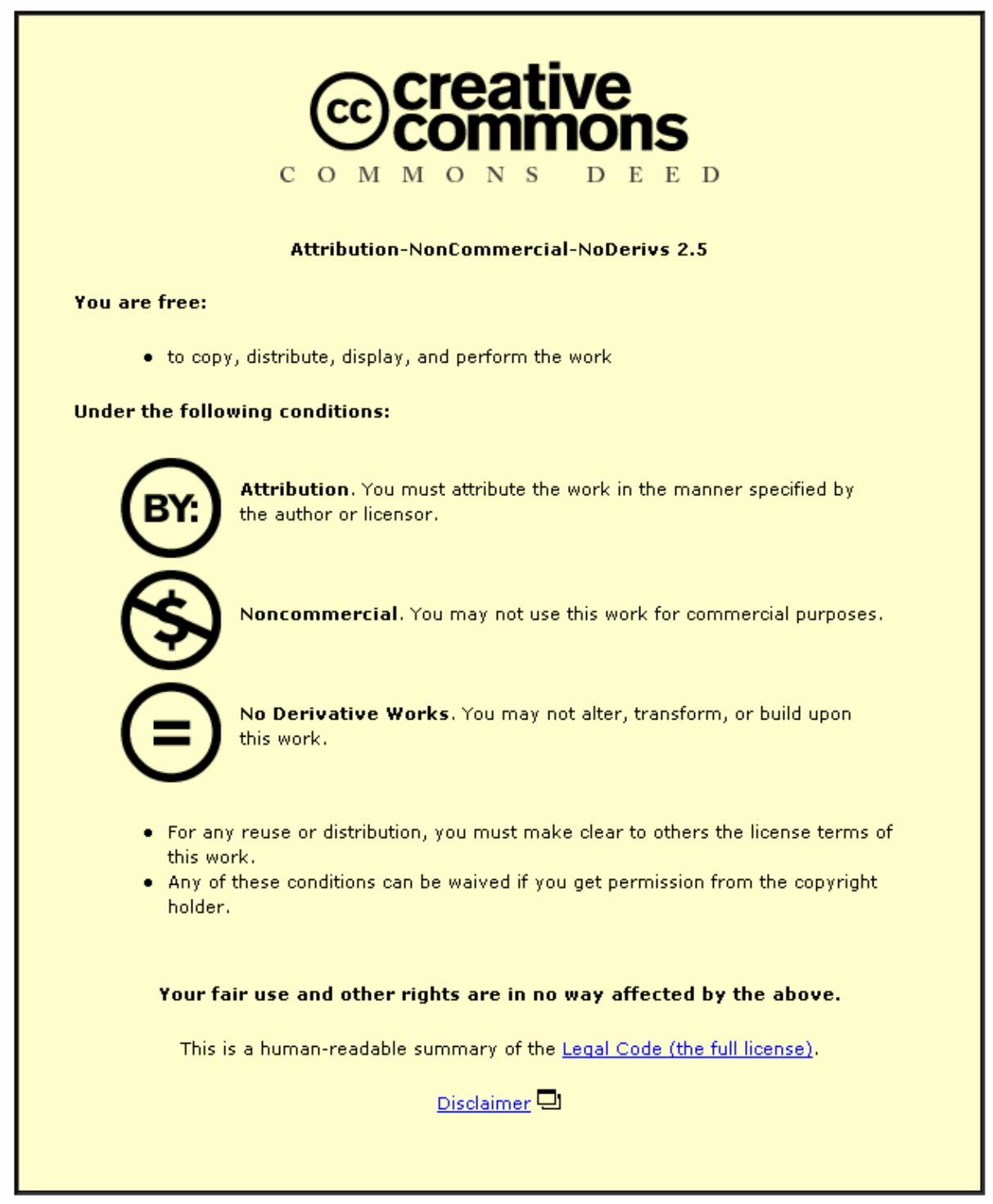

For the full text of this licence, please go to: http://creativecommons.org/licenses/by-nc-nd/2.5/ 


\title{
Calculating the Failure Intensity of a Non-coherent Fault Tree Using the BDD Technique
}

\author{
Sally Beeson and John Andrews \\ Department of Systems Engineering \\ Loughborough University
}

\begin{abstract}
This paper considers a technique for calculating the unconditional failure intensity of any given non-coherent fault tree. Conventional Fault Tree Analysis (FTA) techniques involve the evaluation of lengthy series expansions and approximations are unavoidable even for moderate sized fault trees. The Binary Decision Diagram (BDD) technique overcomes some of the shortfalls of conventional FTA techniques enabling efficient and exact quantitative analysis of both coherent and non-coherent fault trees.
\end{abstract}

Keywords: Non-coherent, Binary Decision Diagrams, Unconditional Failure Intensity, and Birnbaum's Measure of Reliability Importance.

\section{Introduction}

The Binary Decision Diagram (BDD) technique developed by Rauzy in the early 1990's has been shown to significantly improve the accuracy and efficiency of conventional fault tree analysis for coherent systems [1]. More recently attention has focused on the analysis of non-coherent systems using the BDD method. The top event probability can be calculated directly from the SFBDD, which encodes the structure function for a non-coherent fault tree. Quantification of the failure frequency of non-coherent systems could be accomplished by conventional fault tree methods [5]. In 2001 an extension of Birnbaum's measure of importance for the analysis of non-coherent systems was developed [4]. This extension can be used to calculate the unconditional failure intensity of a non-coherent fault tree directly from the SFBDD. This provides an exact and efficient means of calculating this parameter and is described in this paper. 


\section{Non-coherent Systems}

Fault Tree structures can be categorised as either coherent or non-coherent according to their underlying logic. If during fault tree construction the failure logic is restricted to the use of the AND gate and the OR gate, the resulting fault tree is said to be coherent. If however, the NOT gate is used or directly implied, the resulting fault tree can be non-coherent. A more precise definition of coherency can be obtained by considering the structure function of the fault tree [2].

A fault tree is coherent if its structure function $\phi(\mathbf{x})$ complies with the definition of coherency given by the properties of relevance and monotonicity. The first condition requires that each component is relevant; this means that each component contributes to the system state.

$$
\phi\left(1_{\mathrm{i}}, \mathbf{x}\right) \neq \phi\left(0_{\mathrm{i}}, \mathbf{x}\right) \quad \text { for some } \mathbf{x}
$$

The second condition requires the structure function of the fault tree to be monotonically increasing, i.e. non-decreasing.

$$
\phi\left(1_{\mathrm{i}}, \mathbf{x}\right) \geq \phi\left(0_{\mathrm{i}}, \mathbf{x}\right) \quad \forall \mathrm{i}
$$

Where:

$\phi\left(1_{\mathrm{i}}, \mathbf{x}\right)=\phi\left(\mathrm{x}_{1}, \ldots, \mathrm{x}_{\mathrm{i}-1}, 1, \mathrm{x}_{\mathrm{i}+1}, \ldots, \mathrm{x}_{\mathrm{n}}\right)$

$\phi\left(0_{\mathrm{i}}, \mathbf{x}\right)=\phi\left(\mathrm{x}_{1}, \ldots, \mathrm{x}_{\mathrm{i}-1}, 0, \mathrm{x}_{\mathrm{i}+1}, \ldots, \mathrm{x}_{\mathrm{n}}\right)$

The structure function of a fault tree is monotonically increasing (non-decreasing) if as the state of a component deteriorates the system state either remains the same or also deteriorates. The three possibilities, depending on the state of the remaining components, are shown in figure 1. So the system either remains in the same state (working or failed) when component i fails.
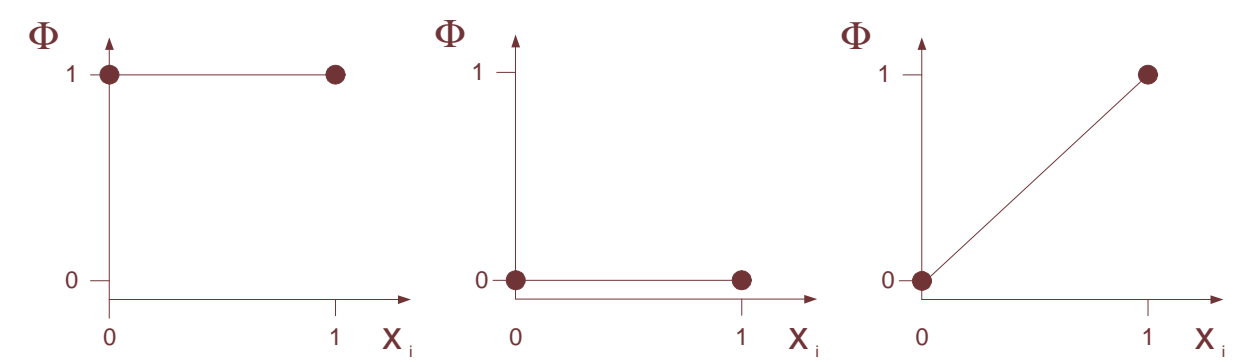

Figure 1: Non-Decreasing Structure Functions

For a structure function of a non-coherent system the remaining possibility, shown in figure 2, can also occur. This system is non-coherent for component i, hence, for some 
state of the remaining components, the system is in a failed state when component $\mathrm{i}$ works and a working state when component i fails.

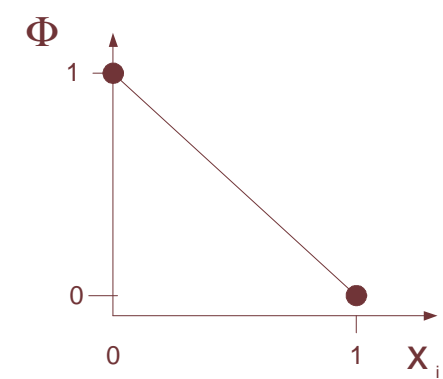

Figure 2: Non-coherent Structure Function

\section{Calculating the SFBDD of a Non-coherent Fault Tree}

Rauzy [1] developed the If-Then-Else (ite) method for computing a SFBDD for a coherent fault tree in 1993. This method has the advantage of producing a SFBDD, which encodes Shannon's formula, i.e., if $f(\mathbf{x})$ is the Boolean function for the top event of the fault tree, then by pivoting about variable $x_{i}$, Shannon's theorem states:

$$
f(\mathbf{x})=x_{i} f_{1}+\bar{x}_{i} f_{2}
$$

Where $f_{1}$ and $f_{2}$ are Boolean functions:

$\mathrm{f}_{1}=\mathrm{f}\left(\mathrm{x}_{1}, \mathrm{x}_{2}, \ldots \ldots . . ., \mathrm{x}_{\mathrm{i}-1}, 1, \mathrm{x}_{\mathrm{i}+1}, \ldots . \mathrm{x}_{\mathrm{n}}\right)$

$f_{2}=f\left(x_{1}, x_{2}, \ldots \ldots . . ., x_{i-1}, 0, x_{i+1}, \ldots . x_{n}\right)$

This is represented by the ite structure given in equation (1).

$$
\text { ite }\left(\mathrm{x}_{\mathrm{i}}, \mathrm{f}_{1}, \mathrm{f}_{2}\right)
$$

Where $x_{i}$ represents a variable and $f_{1}$ and $f_{2}$ represent logic functions. This ite structure is interpreted as follows:

If $\mathrm{x}_{\mathrm{i}}$ fails then consider the logic function $\mathrm{f}_{1}$

else consider the logic function $\mathrm{f}_{2}$.

Thus in the BDD, $\mathrm{f}_{1}$ forms the logic function for the one branch of $\mathrm{x}_{\mathrm{i}}$ and $\mathrm{f}_{2}$ forms the logic function for the zero branch of $\mathrm{x}_{\mathrm{i}}$. Figure 3 shows the diagram that represents this ite structure. 


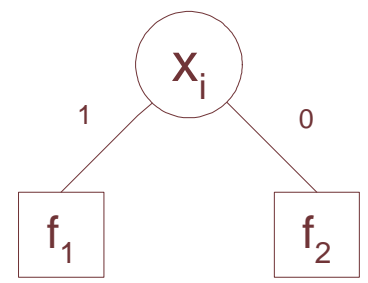

Figure 3: ite structure for ite $\left(\mathrm{x}_{\mathrm{i}}, \mathrm{f}_{1}, \mathrm{f}_{2}\right)$

The process to convert a fault tree structure to a SFBDD first requires a variable ordering scheme to be chosen for the variables (basic events) in the fault tree. Once the variables have been ordered the following procedure is employed to compute the SFBDD.

1. Assign each basic event $\mathrm{x}_{\mathrm{i}}$ in the fault tree an ite structure,

2. Modify the fault tree structure so that each gate has only two inputs

3. Apply De Morgan's rules to push the Not logic down to the basic events:

$$
\begin{aligned}
& \overline{A \cdot B}=\bar{A}+\bar{B} \\
& \bar{A}+B=\bar{A} \cdot \bar{B}
\end{aligned}
$$

where AND is represented by '.' And OR by '+'.

4. Consider each gate in a bottom-up fashion

5. If two gate inputs are $\mathrm{J}$ and $\mathrm{H}$ such that:

$$
\mathrm{J}=\mathrm{ite}(\mathrm{x}, \mathrm{F} 1, \mathrm{~F} 2) \quad \mathrm{H}=\mathrm{ite}(\mathrm{y}, \mathrm{G} 1, \mathrm{G} 2)
$$

Then the following rules are applied:

- If $\mathrm{x}<\mathrm{y}, \mathrm{J}<\mathrm{op}>\mathrm{H}=\mathrm{ite}(\mathrm{x}, \mathrm{F} 1<\mathrm{op}>\mathrm{H}, \mathrm{F} 2<\mathrm{op}>\mathrm{H})$

- If $\mathrm{x}=\mathrm{y}, \mathrm{J}<\mathrm{op}>\mathrm{H}=\mathrm{ite}(\mathrm{x}, \mathrm{F} 1<\mathrm{op}>\mathrm{G} 1, \mathrm{~F} 2<\mathrm{op}>\mathrm{G} 2)$

These rules are used in conjunction with the following identities:

$$
\begin{array}{ll}
1<\mathrm{op}>\mathrm{H}=\mathrm{H}, \quad 0<\mathrm{op}>\mathrm{H}=0 & \text { if }<\mathrm{op}>\text { is an AND gate } \\
1<\mathrm{op}>\mathrm{H}=1, \quad 0<\mathrm{op}>\mathrm{H}=\mathrm{H} & \text { if }<\mathrm{op}>\text { is an OR gate }
\end{array}
$$

Where <op> describes the Boolean operation of the logic gates (AND, OR) of the fault tree.

To illustrate this procedure, consider the fault tree shown in figure 4. 


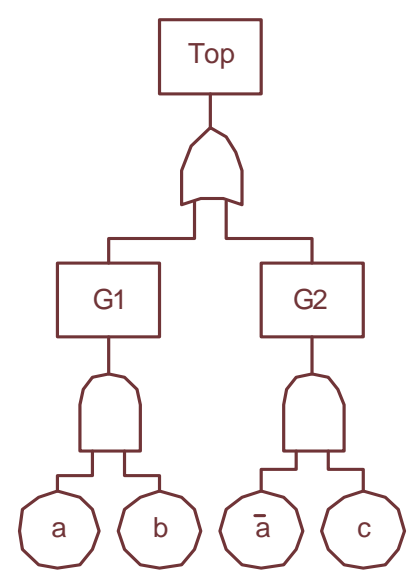

Figure 4: Non-coherent Fault Tree Diagram

Assuming a variable ordering $\mathrm{a}<\mathrm{b}<\mathrm{c}$ :

Assigning each basic event an ite structure:

$$
\begin{aligned}
& a=i \operatorname{te}(a, 1,0) \\
& \bar{a}=i \operatorname{te}(a, 0,1) \\
& b=i \operatorname{te}(b, 1,0) \\
& c=i \operatorname{te}(c, 1,0)
\end{aligned}
$$

Considering the gates in a bottom-up fashion according to the rules and identities introduced above, beginning with gate $\mathrm{G} 1$ :

$\mathrm{G} 1=\mathrm{a} \cdot \mathrm{b}$

$\mathrm{G} 1=\mathrm{ite}(\mathrm{a}, 1,0)$.ite $(\mathrm{b}, 1,0)$

G1=ite $(a,[1 . i t e(b, 1,0)],[0 . i t e(b, 1,0)])$

$\mathrm{G} 1=\mathrm{ite}(\mathrm{a}, \mathrm{ite}(\mathrm{b}, 1,0), 0)$

Now dealing with gate G2:

$\mathrm{G} 2=\overline{\mathrm{a}} \cdot \mathrm{c}$

$\mathrm{G} 2=$ ite $(\mathrm{a}, 0,1) \cdot$ ite $(\mathrm{c}, 1,0)$

$\mathrm{G} 2=\operatorname{ite}(\mathrm{a},[0 . i \operatorname{te}(\mathrm{c}, 1,0)],[1 . \mathrm{ite}(\mathrm{c}, 1,0)])$

$\mathrm{G} 2=$ ite $(\mathrm{a}, 0$, ite $(\mathrm{c}, 1,0)$

Finally dealing with the top gate, Top:

$\mathrm{Top}=\mathrm{G} 1+\mathrm{G} 2$ 
Top=ite $(\mathrm{a}$, ite $(\mathrm{b}, 1,0), 0)+\mathrm{ite}(\mathrm{a}, 0$, ite $(\mathrm{c}, 1,0))$

Top=ite $(\mathrm{a},[$ ite $(\mathrm{b}, 1,0)+0],[0+\mathrm{ite}(\mathrm{c}, 1,0)])$

Top=ite $(\mathrm{a}$, ite $(b, 1,0)$, ite $(c, 1,0))$

The ite structure computed for the fault tree shown in figure 4, is given in equation 2 and the SFBDD is shown in figure 5.

$$
\text { ite }(\mathrm{a}, \text { ite }(\mathrm{b}, 1,0), \text { ite }(\mathrm{c}, 1,0))
$$

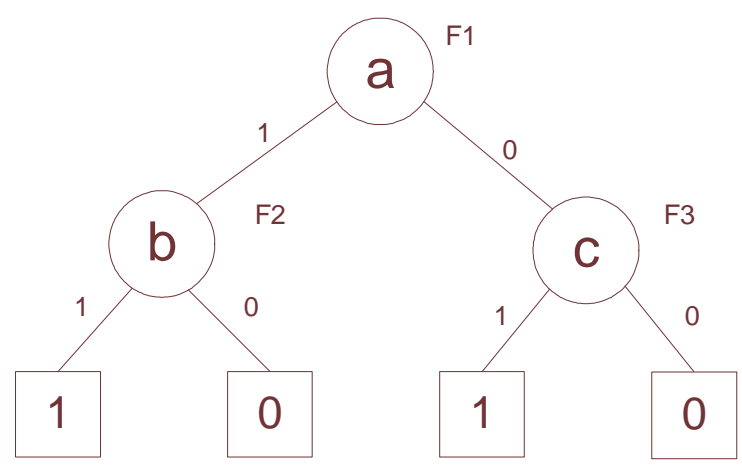

Figure 5: SFBDD Obtained for the Non-coherent Fault Tree in Figure 4

\section{The Unconditional Failure Intensity of a Coherent System}

The unconditional failure intensity is denoted by $\mathrm{w}_{\text {sys }}(\mathrm{t})$ and defined as the probability that a system fails per unit time at $\mathrm{t}$ given that it was working at $\mathrm{t}=0$. This is an important system parameter to calculate during quantification since, having determined $\mathrm{w}_{\text {sys }}(\mathrm{t})$ the expected number of system failures in a given interval, $\mathrm{W}_{\text {sys }}(0, \mathrm{t})$ can be calculated:

$$
\mathrm{W}_{\mathrm{SYS}}(0, \mathrm{t})=\int_{0}^{\mathrm{t}} \mathrm{w}_{\mathrm{SYS}}(\mathrm{u}) \mathrm{du}
$$

The unconditional failure intensity of a coherent system can be expressed in terms of the criticality function, $\mathrm{G}_{\mathrm{i}}(\mathbf{q})$.

$$
w_{\text {sys }}(t)=\sum_{i=1}^{n_{c}} G_{i}(q) w_{i}(t)
$$

Where, $\mathrm{w}_{\mathrm{i}}(\mathrm{t})$ is the failure intensity of component $\mathrm{i}$, and $\mathrm{n}_{\mathrm{c}}$ is the total number of components. 
The criticality function, also known as Birnbaum's measure of component reliability importance, denoted by, $\mathrm{G}_{\mathrm{i}}(\mathbf{q})$, is defined as the probability that the system is in a working but critical state for component i such that the failure of component $i$ would cause system failure. This can be calculated from:

$$
\mathrm{G}_{\mathrm{i}}(\mathbf{q})=\mathrm{Q}_{\text {sys }}\left(1_{\mathrm{i}}, \mathbf{q}\right)-\mathrm{Q}_{\text {sys }}\left(0_{\mathrm{i}}, \mathbf{q}\right)
$$

Where:

$\mathrm{Q}_{\text {sys }}\left(1_{\mathrm{i}}, \mathbf{q}\right)=\mathrm{Q}_{\text {sys }}\left(\mathrm{x}_{1}, \mathrm{x}_{2}, \ldots . ., \mathrm{x}_{\mathrm{i}-1}, 1, \mathrm{x}_{\mathrm{i}+1}, \ldots . ., \mathrm{x}_{\mathrm{n}}\right)$ is the probability that the system has failed and component $i$ is failed.

$\mathrm{Q}_{\text {sys }}\left(0_{\mathrm{i}}, \mathbf{q}\right)=\mathrm{Q}_{\text {sys }}\left(\mathrm{x}_{1}, \mathrm{x}_{2}, \ldots \ldots, \mathrm{x}_{\mathrm{i}-1}, 0, \mathrm{x}_{\mathrm{i}+1}, \ldots . ., \mathrm{x}_{\mathrm{n}}\right)$ is the probability that the system has failed and component $\mathrm{i}$ is working.

$\mathrm{q}_{\mathrm{i}}$ is the probability that component I fails.

Equation 3 enables efficient and accurate calculation of the unconditional failure intensity using the BDD technique.

\section{The Concept of Component Relevancy / Irrelevancy}

When analysing non-coherent fault trees, both component failed states and component working states can contribute to system failure. A component can be either relevant to the system state or irrelevant to the system state. If a component is relevant to the system state, it can be either failure relevant or repair relevant. Component $i$ is said to be failure relevant if the system is in a critical state such that the failure of component i would cause the system to fail. Similarly component $i$ is said to be repair relevant if the system is in a critical state such that the repair of component $i$ would cause system failure. Finally component $\mathrm{i}$ is said to be irrelevant if its state has no bearing on the state of the system.

Expressions for the failure relevance and irrelevance of a component can be obtained from the Boolean expression for the top event. Consider the Boolean expression for the top even, Top, given in equation 5 .

$$
\mathrm{Top}=\mathrm{ab}+\overline{\mathrm{a}} \mathrm{d}+\mathrm{ce}+\mathrm{bd}
$$


An expression for the failure relevance or irrelevance of component a denoted by, Top $_{\mathrm{a}=1}$, can be obtained by substituting the value 1 for component a into equation 5 .

$$
\begin{aligned}
\operatorname{Top}_{\mathrm{a}=1} & =\mathrm{b}+\mathrm{ce}+\mathrm{bd} \\
& =\mathrm{b}+\mathrm{ce}
\end{aligned}
$$

Similarly an expression for the repair relevance or irrelevance of component a denoted by, Top $\mathrm{a}=0$, can be obtained by substituting the value 0 for component a into equation 5.

$$
\operatorname{Top}_{\mathrm{a}=0}=\mathrm{d}+\mathrm{ce}+\mathrm{bd}=\mathrm{d}+\mathrm{ce}
$$

An expression for the irrelevance of component $\mathrm{a}$, denoted by, Top ${ }_{\mathrm{a}={ }^{\prime},}$, is obtained by taking the product of $\mathrm{Top}_{\mathrm{a}=1}$ and $\mathrm{Top}_{\mathrm{a}=0 \text {. }}$.

$$
\begin{aligned}
\operatorname{Top}_{\mathrm{a}_{\mathrm{a}}{ }_{-},} & =\operatorname{Top}_{\mathrm{a}=1} \cdot \operatorname{Top}_{\mathrm{a}=0} \\
& =(\mathrm{b}+\mathrm{ce})(\mathrm{d}+\mathrm{ce}) \\
& =\mathrm{bd}+\mathrm{ce}
\end{aligned}
$$

\section{An Extension of Birnbaum's Measure of Importance for Non-coherent Fault Trees}

Birnbaum's measure of component reliability is a fundamental probabilistic measure of importance [3]. However, Birnbaum developed this measure strictly for the analysis of coherent systems. In 2001 an extension of Birnbaum's measure of importance for the analysis of non-coherent structures was developed [4].

When dealing with a coherent system, system failure can only be caused by component failure. Hence a component in a coherent system can only be failure critical. However, when dealing with a non-coherent system, system failure can be caused not only by the failure of component i, (i) but also by the repair of component I, $(\bar{i})$. Thus a component in a non-coherent system can be failure critical or repair critical. These two criticalities must be considered separately since component i can exist in only one state at any time. 
The probability that component $\mathrm{i}$ is critical to system failure, can be expressed as the probability that component $\mathrm{i}$ is repair critical, $\mathrm{G}_{\mathrm{i}}^{\mathrm{R}}(\mathbf{q})$, or the probability that component $\mathrm{i}$ is failure critical, $\mathrm{G}_{\mathrm{i}}^{\mathrm{F}}(\mathbf{q})$.

$$
\mathrm{G}_{\mathrm{i}}(\mathbf{q})=\mathrm{G}_{\mathrm{i}}^{\mathrm{R}}(\mathbf{q})+\mathrm{G}_{\mathrm{i}}^{\mathrm{F}}(\mathbf{q})
$$

This can be obtained from the system unavailability function $\mathrm{Q}_{\text {sys }}(\mathrm{t})$ that can be determined from Henley and Inagaki's calculation procedure outlined in [5]. Component $i$ is failure critical if the system is working, but will fail if component $i$ fails. Thus the probability that component $\mathrm{i}$ is failure critical is the probability that the system is in a working state such that the failure of component $\mathrm{i}$ causes at least one prime implicant set containing event $\mathrm{i}$ to occur. This probability is calculated by obtaining the probability that at least one prime implicant set containing event $i$ exists at time $t$ and then dividing this probability by the unavailability of component $i$.

To calculate this probability it is first helpful to re-express the system unavailability as three distinct terms having expressed it in the form used by Inagaki and Henley

$$
\text { Qsys }(\mathrm{t})=\mathrm{q}_{\mathrm{i}} \operatorname{Pr}[\mathrm{A}]+\mathrm{p}_{\mathrm{i}} \operatorname{Pr}[\mathrm{B}]+\operatorname{Pr}[\mathrm{C}]
$$

The three terms of this equation are grouped so that $\operatorname{Pr}[\mathrm{A}]$ represents the probability terms which appear together with the failure probability of component $i, \operatorname{Pr}[\mathrm{B}]$ represents the probability terms which appear together with the functioning probability of component i $\left(p_{i}=1-q_{i}\right)$, and $\operatorname{Pr}[\mathrm{C}]$ represents the probability terms which do not contain $\mathrm{q}_{\mathrm{i}}$ or $\mathrm{p}_{\mathrm{i}}$, i.e. for which component $\mathrm{i}$ is irrelevant respectively.

Now the probability that component $\mathrm{i}$ is failure critical is calculated as follows:

$$
G_{i}^{F}(\mathbf{q})=\frac{\partial Q_{S Y S}}{\partial q_{i}}=\operatorname{Pr}[A]
$$

Similarly the probability that component $\mathrm{i}$ is repair critical is the probability that the system is in a working state such that the repair of component $\mathrm{i}$ causes at least one prime implicant set containing event $\overline{\mathrm{i}}$ to occur. This is calculated as follows:

$$
G_{i}^{R}(\mathbf{q})=\frac{\partial Q_{S Y S}}{\partial p_{i}}=\operatorname{Pr}[B]
$$


The top event can only exist at time $t$ if at least one prime implicant set exists at time t. Hence the failure and repair criticality can be calculated separately by differentiating the system unavailability function, $\mathrm{Q}_{\text {sys }}(\mathrm{t})$, with respect to $\mathrm{q}_{i}$ and $\mathrm{p}_{\mathrm{i}}$ respectively.

The unconditional failure intensity for a coherent fault tree is expressed in terms of the criticality function, $\mathrm{G}_{\mathrm{i}}(\mathbf{q})$ :

$$
w_{\text {sys }}(t)=\sum_{i=1}^{n_{c}} G_{i}(\mathbf{q}) w_{i}(t)
$$

This can be now be extended to non-coherent systems as follows:

$$
w_{\text {sys }}(t)=\sum_{i=1}^{n_{c}} G_{i}^{F}(\mathbf{q}) w_{i}(t)+\sum_{i=1}^{n_{c}} G_{i}^{R}(\mathbf{q}) v_{i}(t)
$$

where $v_{i}$ is the unconditional repair intensity for component $i$.

This can be then be used to calculate the expected number of system failures in a given interval:

$$
W_{\text {sys }}(0, t)=\int_{0}^{t} \sum_{i=1}^{n_{c}} G_{i}^{F}(\mathbf{q}) w_{i}(u)+\sum_{i=1}^{n_{c}} G_{i}^{R}(\mathbf{q}) v_{i}(u) d u
$$

The first term on the right hand side of equation (12) calculates the number of occurrences of system failure due to the failure of component $\mathrm{i}$ in a given interval. The second term calculates the number of occurrences of system failure due to the repair of component $\mathrm{i}$ in a given interval.

\section{Calculating the Unconditional Failure Intensity of a Non-coherent Fault Tree Using the BDD Method}

The BDD Method has been extended to enable full and exact analysis of non-coherent fault trees $[6,7]$.

The expressions for calculating Birnbaum's measures of component failure and repair importance are given in equations 8 and 9 respectively. 
From the definition of component relevance / irrelevance given in section 6, it is possible to define Birnbaum's measure of component failure importance as the probability that component $\mathrm{i}$ is failure relevant to the system state [6] given by:

$$
\mathrm{G}_{\mathrm{i}}^{\mathrm{F}}(\mathbf{q})=\mathrm{E}\left[\phi_{\mathrm{i}=1}\right]-\mathrm{E}\left[\phi_{\mathrm{i}={ }^{\prime},}{ }^{\prime}\right]
$$

Where:

$\mathrm{E}\left[\phi_{\mathrm{i}=1}\right]$ is the probability that component $\mathrm{i}$ is either failure relevant or irrelevant to the state of the system.

$\mathrm{E}\left[\phi_{\mathrm{i}={ }^{\prime}},\right]$ is the probability that component $\mathrm{i}$ is irrelevant to the state of the system.

Similarly, Birnbaum's measure of component repair importance can be defined as the probability that component $\mathrm{i}$ is repair relevant to the system state:

$$
\mathrm{G}_{\mathrm{i}}^{\mathrm{R}}(\mathbf{q})=\mathrm{E}\left[\phi_{\mathrm{i}=0}\right]-\mathrm{E}\left[\phi_{\mathrm{i}={ }^{\prime}{ }^{\prime}}\right]
$$

Where:

$\mathrm{E}\left[\phi_{\mathrm{i}=0}\right]$ is the probability that component $\mathrm{i}$ is either repair relevant or irrelevant to the system state.

$\phi_{\mathrm{i}=1}, \phi_{\mathrm{i}=0,} \phi_{\mathrm{i}={ }^{-} \text {, }}$ are the structure function with $\mathrm{x}_{\mathrm{i}}=1,0$ and '-' respectively.

It is possible to calculate $\mathrm{E}\left[\phi_{\mathrm{i}=1}\right], \mathrm{E}\left[\phi_{\mathrm{i}=0}\right]$ directly from the SFBDD, the procedure for calculating these probabilities is outlined below:

$$
\begin{aligned}
& E\left[\phi_{i=1}\right]=\sum_{x_{i}} \operatorname{Pr}_{\mathrm{xi}}(\mathbf{q}) \cdot \operatorname{Po}_{\mathrm{xi}}{ }^{1}(\mathbf{q}) \\
& E\left[\phi_{i=0}\right]=\sum_{x_{i}} \operatorname{Pr}_{\mathrm{xi}}(\mathbf{q}) \cdot \operatorname{Po}_{\mathrm{xi}}{ }^{0}(\mathbf{q})
\end{aligned}
$$

Where:

$\operatorname{Pr}_{\mathrm{xi}}(\mathbf{q})$ is the probability of the path section from the root vertex to node $\mathrm{x}_{\mathrm{i}}$. $\mathrm{Po}_{\mathrm{xi}}{ }^{1}(\mathbf{q})$ is the probability of the path section from the one branch of node $\mathrm{x}_{\mathrm{i}}$ to a terminal 1 node (excluding the probability of $\mathrm{x}_{\mathrm{i}}$ ).

$\operatorname{Po}_{\mathrm{xi}}{ }^{0}(\mathbf{q})$ is the probability of the path section from the zero branch of node $\mathrm{x}_{\mathrm{i}}$ to a terminal 1 node (excluding the probability of $\mathrm{x}_{\mathrm{i}}$ ). 
Although $\mathrm{E}\left[\phi_{\mathrm{i}=}{ }_{-},\right]$can be calculated by taking the expectation of the logical product of

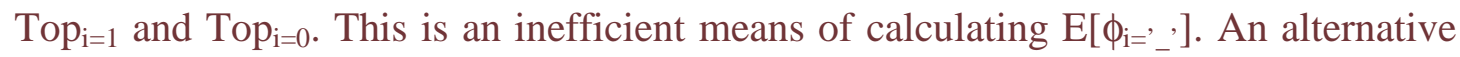
technique can be employed which involves computing an intermediate BDD for each node from which $\mathrm{E}\left[\phi_{\mathrm{i}={ }_{-}}{ }^{\prime}\right]$ can be efficiently calculated. The intermediate BDD for each node is obtained by ANDing the one and zero branches of the node. An expression for $\mathrm{E}\left[\phi_{\mathrm{i}=}{ }_{-},\right]$is then calculated by multiplying the probability preceding the node in the SFBDD by the probability of the sum of all the terminal one paths through the intermediate BDD. To illustrate this technique consider again the SFBDD calculated in section 3 , figure 5 .

The ite table for this BDD shown in table 1.

\begin{tabular}{|c|c|c|c|}
\hline Node & Variable & 1 branch & 0 branch \\
\hline F1 & a & F2 & F3 \\
\hline F2 & b & 1 & 0 \\
\hline F3 & c & 1 & 0 \\
\hline
\end{tabular}

Table 1: ite Table

The next stage is to calculate each of the terms in equations 15 and 16 . The first term, $\operatorname{Pr}_{\mathrm{xi}}(\mathbf{q})$ is the probability of the path from the root vertex to node $\mathrm{x}_{\mathrm{i}}$, which is recorded in Table 2.

\begin{tabular}{|c|c|l|}
\hline Node & $\operatorname{Pr}_{\mathrm{xi}}(\mathbf{q})$ & Comment \\
\hline F1 & 1 & Root vertex itself \\
\hline F2 & $\mathrm{q}_{\mathrm{a}}$ & F2 reached via the one branch of node F1 \\
\hline F3 & $\mathrm{p}_{\mathrm{a}}$ & F3 reached via the zero branch of node F1 \\
\hline
\end{tabular}

Table 2: $\operatorname{Pr}_{\mathrm{xi}}(\mathbf{q})$ for each node in the SFBDD in figure 5

The $\mathrm{Po}_{\mathrm{xi}}{ }^{1}(\mathbf{q})$ term is calculated by summing the probability of all the paths from the selected node, $\mathrm{x}_{\mathrm{i}}$, along the one branch to a terminal 1 vertex, excluding the probability of the selected node. Table 3 records $\operatorname{Po}_{x i}{ }^{1}(\mathbf{q})$ for each node. 


\begin{tabular}{|c|c|l|}
\hline Node & $\mathrm{Po}_{\mathrm{xi}}{ }^{1}(\mathbf{q})$ & Comment \\
\hline $\mathrm{F} 1$ & $\mathrm{q}_{\mathrm{b}}$ & $\begin{array}{l}1 \text { branch of } \mathrm{F} 1 \text { passes to } \mathrm{F} 2 \text { and the 1 branch of } \mathrm{F} 2 \\
\text { passes to a terminal 1 node }\end{array}$ \\
\hline $\mathrm{F} 2$ & 1 & 1 branch of F2 passes to a terminal 1 node \\
\hline F3 & 1 & 1 branch of F3 passes to a terminal 1 node \\
\hline
\end{tabular}

Table 3: $\mathrm{Po}_{\mathrm{xi}}{ }^{1}(\mathbf{q})$ each node in the SFBDD in figure 5

Similarly $\operatorname{Po}_{x i}{ }^{0}(\mathbf{q})$ is calculated by summing the probability of all the paths from the selected node $\mathrm{x}_{\mathrm{i}}$, along the zero branch to a terminal 1 vertex, excluding the probability of the selected node. Table 4 records $\operatorname{Po}_{x i}{ }^{0}(\mathbf{q})$ for each node.

\begin{tabular}{|c|c|l|}
\hline Node & $\mathrm{po}_{\mathrm{xi}}{ }^{0}(\mathbf{q})$ & Comment \\
\hline $\mathrm{F} 1$ & $\mathrm{q}_{\mathrm{c}}$ & $\begin{array}{l}\text { 0 branch of F1 passes to F3 and the 1 branch of F3 } \\
\text { passes to a terminal 1 node }\end{array}$ \\
\hline F2 & 0 & No terminal one paths \\
\hline F3 & 0 & No terminal one paths \\
\hline
\end{tabular}

Table 4: $\mathrm{Po}_{\mathrm{xi}}{ }^{0}(\mathbf{q})$ for each node in the SFBDD in figure 5

Finally $E\left[\phi_{\mathrm{i}=},{ }_{-}\right]$must be calculated for each of the nodes in the SFBDD. The calculation procedure requires some additional work. An intermediate BDD must be calculated for each node $\mathrm{x}_{\mathrm{i}}$. The probability of the sum of the disjoint paths through this intermediate BDD is calculated and multiplied by the probability preceding the node $\mathrm{x}_{\mathrm{i}}$ to give $\mathrm{E}\left[\phi_{\mathrm{i}={ }_{-},}\right]$. The intermediate BDD is computed by ANDing the one and zero branches of a node. Each of the nodes in the SFBDD in figure 5 will be considered below:

\section{Dealing with node F1}

$$
\begin{aligned}
\text { F2.F3 } & =i t e(b, 1,0) . i t e(c, 1,0) \\
& =i t e(b, i t e(c, 1,0), 0)
\end{aligned}
$$

The resulting BDD is shown in figure 6: 


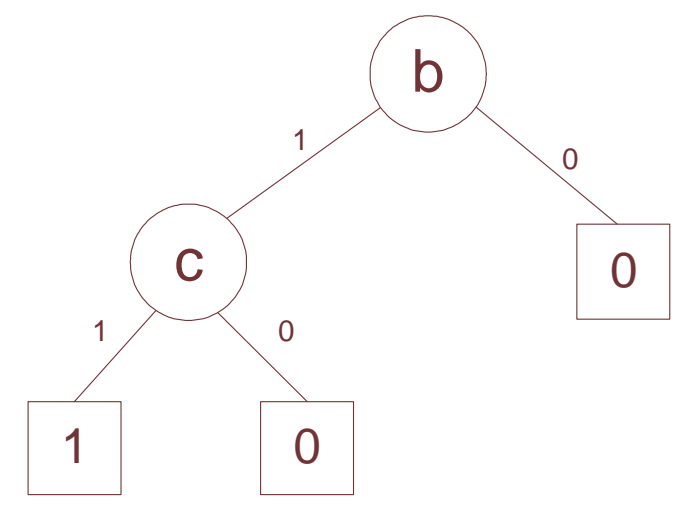

Figure 6: Intermediate BDD for Node F1

There is one terminal path through this BDD, bc, the probability of this path is: $\mathrm{q}_{\mathrm{b}} \mathrm{q}_{\mathrm{c}}$

Dealing with node F2:

$1.0=0$

The probability of this is zero.

Dealing with node F3:

$1.0=0$

The probability of this is zero.

Table 5 summarises the results obtained for $\mathrm{E}\left[\phi_{\mathrm{i}=1}\right], \mathrm{E}\left[\phi_{\mathrm{i}=0}\right]$ and $\mathrm{E}\left[\phi_{\mathrm{i}={ }_{-},}\right]$.

\begin{tabular}{|c|c|c|c|c|}
\hline Node & Variable (i) & $\mathrm{E}\left[\phi_{\mathrm{i}=1}\right]$ & $\mathrm{E}\left[\phi_{\mathrm{i}=0}\right]$ & $\mathrm{E}\left[\phi_{\mathrm{i}={ }_{-},}\right]$ \\
\hline F1 & $\mathrm{a}$ & $\mathrm{q}_{\mathrm{b}}$ & $\mathrm{q}_{\mathrm{c}}$ & $\mathrm{q}_{\mathrm{b}} \mathrm{q}_{\mathrm{c}}$ \\
\hline F2 & $\mathrm{b}$ & $\mathrm{q}_{\mathrm{a}}$ & 0 & 0 \\
\hline F3 & $\mathrm{c}$ & $\mathrm{p}_{\mathrm{a}}$ & 0 & 0 \\
\hline
\end{tabular}

Table 5: Summary of results obtained for $\mathrm{E}\left[\phi_{\mathrm{i}=1}\right], \mathrm{E}\left[\phi_{\mathrm{i}=0}\right]$ and $\mathrm{E}\left[\phi_{\mathrm{i}={ }^{\prime}{ }_{-}}\right]$

From the results in table 5 and equations 13 and 14 the failure and repair importance of each component is obtained as follows:
$\mathrm{G}_{\mathrm{a}}^{\mathrm{F}}(\mathbf{q})=\mathrm{q}_{\mathrm{b}}-\mathrm{q}_{\mathrm{b}} \mathrm{q}_{\mathrm{c}}$
$\mathrm{G}_{\mathrm{a}}^{\mathrm{R}}(\mathbf{q})=\mathrm{q}_{\mathrm{c}}-\mathrm{q}_{\mathrm{b}} \mathrm{q}_{\mathrm{c}}$
$\mathrm{G}_{\mathrm{b}}{ }^{\mathrm{F}}(\mathbf{q})=\mathrm{q}_{\mathrm{a}}$
$\mathrm{G}_{\mathrm{b}}{ }^{\mathrm{R}}(\mathbf{q})=0$
$\mathrm{G}_{\mathrm{c}}{ }^{\mathrm{F}}(\mathbf{q})=\mathrm{p}_{\mathrm{a}}$
$\mathrm{G}_{\mathrm{c}}{ }^{\mathrm{R}}(\mathbf{q})=0$ 
From this it is possible to calculate the unconditional failure intensity and then the expected number of system failures in a given interval using equations 11 and 12 respectively.

$$
\begin{aligned}
\mathrm{w}_{\mathrm{sys}}(\mathrm{t}) & =\left(\mathrm{q}_{\mathrm{b}}-\mathrm{q}_{\mathrm{b}} \mathrm{q}_{\mathrm{c}}\right) \mathrm{w}_{\mathrm{a}}+\mathrm{q}_{\mathrm{a}} \mathrm{w}_{\mathrm{b}}+\mathrm{p}_{\mathrm{a}} \mathrm{w}_{\mathrm{c}}+\left(\mathrm{q}_{\mathrm{c}}-\mathrm{q}_{\mathrm{b}} \mathrm{q}_{\mathrm{c}}\right) \mathrm{v}_{\mathrm{a}} \\
& =\left(1-\mathrm{q}_{\mathrm{c}}\right) \mathrm{q}_{\mathrm{b}} \mathrm{w}_{\mathrm{a}}+\mathrm{q}_{\mathrm{a}} \mathrm{w}_{\mathrm{b}}+\mathrm{p}_{\mathrm{a}} \mathrm{w}_{\mathrm{c}}+\left(1-\mathrm{q}_{\mathrm{b}}\right) \mathrm{q}_{\mathrm{c}} \mathrm{v}_{\mathrm{a}}
\end{aligned}
$$

\section{Conclusion}

The unconditional failure intensity is a key parameter to calculate during fault tree quantification. Once the unconditional failure intensity is known it is possible to calculate the expected number of system failures in a given interval. Until now it has not been possible to calculate the unconditional failure intensity of a non-coherent fault tree using the BDD method. In 2001 an extension of Birnbaum's measure of reliability importance to enable the analysis of non-coherent systems was developed. This measure can be used to calculate the unconditional failure intensity of a noncoherent fault tree efficiently and accurately using the BDD method.

\section{References}

1. A. Rauzy, "New Algorithms for Fault Tree Analysis", Reliability Engineering and System Safety, vol. 40, 1993, p203-211.

2. A. Bendall and J. Ansell, "The Incoherency of Multistate Coherent Systems", Reliability Engineering, Vol. 8, 1984, pp165-178.

3. Z. W. Birnbaum, "On the Importance of Different Components in a Multicomponent System", Multivariate Analysis II, PR Krishnaiah, ed, Academic Press, 1969.

4. S. Beeson and J. D. Andrews, "Birnbaum's Measure of Component Importance for Non-coherent Systems", IEEE Transactions on Reliability, in press.

5. Inagaki and E. J. Henley, "Probabilistic Evaluation of Prime Implicants and Top Events for Non-coherent Systems", IEEE Transactions on Reliability, vol. R-29, No. 5, Dec 1980.

6. S. Beeson, "Non-coherent Fault Tree Analysis", Doctoral Thesis, Loughborough University, 2002. 
7. Y. Dutuit and A. Rauzy, "Exact and Truncated Computations of Prime Implicants of Coherent and Non-coherent Fault Trees with Aralia", Reliability Engineering and System Safety, vol. 58, 1997, p127-144. 